\title{
UMA ANTROPOLOGIA NÃO ORTODOXA
}

\author{
UNORTHODOX ANTHROPOLOGY
}

Roque de Barros Laraia ${ }^{1}$

Iniciei a minha carreira como antropólogo tendo como campo de estudo as sociedades indígenas brasileiras e mais especificamente as pertencentes a família linguística Tupi-Guarani. Foi assim que realizei trabalhos de campo entre os Suruí e Akwáwa-Asurini, no Pará; Kamayurá, no Alto Xingu; e Urubu-Kaapor, no Maranhão, próximo a divisa com o Pará. No entanto, no decorrer de minha longa carreira acadêmica nunca tomei essa especialização como uma camisa de força. Acabei por fazer breves incursões em outras áreas da Antropologia. Após minha aposentadoria na Universidade de Brasília, aceitei ocupar posições, não necessariamente acadêmicas, como membro do Conselho Nacional de Imigração e do Conselho Consultivo do Instituto de Patrimônio Artístico e Histórico Nacional, que pelo menos no segundo posto me levou a escrever alguns artigos. Tendo escolhido uma profissão, como a docente, habituei-me muito com a prática da leitura e, também, da escrita. Faço parte de uma geração que tinha a leitura como sua principal ocupação de laser, pois antecedi de muito a implantação da televisão e da internet e, também a do telefone, que são hoje, entre os jovens, os principais competidores dos livros.

Por isto, escolhi como tema desta palestra falar sobre três artigos meus que, embora, publicados em revistas acadêmicas, não são resultados de alguma das minhas pesquisas. Do ponto de vista da ortodoxia de nossa disciplina os nossos trabalhos científicos são resultados normalmente de um projeto de pesquisa, seguido de um longo trabalho de campo, da análise do material coletado, o que possibilita chegar a um resultado prático que pode ser uma dissertação de mestrado, uma tese de doutorado, um artigo em revista cientifica

\footnotetext{
${ }^{1}$ Professor Emérito da Universidade de Brasília (UnB), Brasília, DF; Pesquisador Emérito do CNPq, e-mail: departamentodeantropologia@gmail.com
} 
ou um livro. De um ponto de vista canônico, esses procedimentos somente são possíveis porque possuímos um cabedal teórico e o conhecimento de técnicas e métodos da nossa disciplina.

$\mathrm{O}$ que estou, neste texto, denominando de uma Antropologia não ortodoxa é um produto do conhecimento adquirido em nossa disciplina, mas que não dependeu da aplicação rigorosa dos procedimentos acima apontados. São textos que resultaram de um "insight" inesperado. Normalmente somos nós que escolhemos o tema de nossos artigos científicos. Assim eles sempre têm muito a ver com as pesquisas que realizamos. Mas os textos que pretendo narrar não são resultantes de uma escolha premeditada. Ouso dizer, foram eles que me escolheram.

\section{Texto 1.}

Não me lembro de quando ouvi pela primeira vez a palavra "Lilith" e quando foi que ao consultar uma enciclopédia encontrei uma definição sumária: "demônio feminino, matrona de um movimento feminista americano", mas o meu interesse somente aumentou quando descobri uma nova informação que acrescentava "primeira mulher de Adão".

Foi somente depois de 1992, quando passei um semestre como professor visitante, no Departamento de Antropologia da Universidade Federal do Paraná que comecei a fazer uma pesquisa bibliográfica a respeito. Descobri que no centro de Curitiba, em uma sobreloja, existia uma livraria especializada em livros feministas, "Lilith" era o nome dessa livraria. Ou seja, mais uma vez a palavra Lilith aparece associada a feminismo. Em 1992, como sabem não existia o Google, portanto é possível imaginar como foi difícil a minha busca.

Finalmente, em 1997, publiquei no volume 40, no 1, da Revista de Antropologia, da Universidade de São Paulo, o meu artigo "Jardim do Éden Revisitado".

Comecei o meu artigo com a crítica que o antropólogo britânico Edmund Leach fez a Claude Levi-Strauss que evitou a realização de uma análise estruturalista do Gênesis, sob a alegação de que "a mitologia do Velho Testamento foi distorcida pelas operações 
intelectuais dos editores bíblicos". Essa argumentação foi refutada por Leach, em seu artigo "A Legitimidade de Salomão" no qual demonstrou a existência na Bíblia de evidências etnográficas passíveis de serem analisadas etnograficamente. Concordamos com Leach em suas críticas a Levi-Strauss e, também, quando diz que os antropólogos, acostumados a analisar as mitologias de outros povos, tem um "melindre extraordinário com a análise do Cristianismo e do Judaísmo que são religiões nas quais estão profundamente envolvidos".

Assim, a nossa estratégia de trabalho foi a de considerar que os "editores bíblicos", através dos tempos procuraram mediante uma atitude de censura uma espécie de "pasteurização" do discurso original, numa tentativa de adequá-los aos valores morais e culturais de suas respectivas épocas. Contudo, muito dos trechos que foram objetos de cortes não tiveram os seus registros totalmente apagados, pois continuam disponíveis em outros textos, principalmente os da religião Judaica.

O leitor que ignora a possibilidade de cortes não percebe contradições que ficam evidentes para quem faz uma leitura mais minuciosa.

No sétimo dia da criação, Deus criou o homem á sua imagem: “à imagem de Deus o criou, macho e fêmea os criou" (Gênesis,1, 27). Esta afirmação categórica é uma negativa da versão mais difundida: a de que o homem foi criado antes da mulher.

Entre interpretações diversas escolhi a que me pareceu mais simples, a de que seguindo o exemplo do que foi feito com os animais, Deus teria criado um casal: Adão e uma mulher que antecedeu a Eva. Esta mulher teria sido Lilith, figura bastante conhecida da antiga tradição judaica. Lilith não se submeteu à dominação masculina. A sua maneira de reivindicar igualdade foi a de recusar a forma de relação sexual com o homem por cima. Por isso, fugiu para o Mar Vermelho. Adão queixou-se ao Criador que enviou três anjos em busca da noiva rebelde. Os emissários do Senhor tentaram em vão convencer a fujona. Ameaçaram afogá-la no mar. De acordo com uma lei Sumeriana, "se uma mulher odeia o seu marido e diz para ele "Você não é mais meu marido", ela deve ser lançada no rio. As ameaças não surtiram efeito, por isso foi transformada em um demônio feminino capaz de dizimar recém-nascidos. No entanto, ela 
jurou aos anjos que sempre que avistasse os nomes dos mensageiros de Deus, deixaria a criança em paz".

Segundo a tradição, Lilith seria uma figura sedutora, de longos cabelos, que voa à noite para atacar os homens que dormem sozinhos. As crianças recém-nascidas são as suas principais vitimas. A crença em Lilith, durante muito tempo, serviu para explicar as mortes injustificáveis dos recém-nascidos, como o mal dos sete dias. Uma forma utilizada para proteger as crianças contra a fúria da bela demônia é o de afixar no leito da criança, três fitas, cada uma delas com um nome dos três anjos: Sanvi, Sansavi e Samangelaf. Segundo o Dicionário de Lendas e Tradições, na véspera do Shabat e da Lua Nova, quando uma criança sorri é porque Lilith está brincando com ela. Outra tradição judaica afirma que a lendária Rainha de Sabá que teria visitado Salomão nada mais era do que Lilith. O sábio rei, contudo, descobriu o ardil, ao levantar a sai da rainha e constatar que as suas pernas eram peludas.

A rebelião de Lilith contra Adão e o próprio Criador levou à necessidade da criação de Eva, esta sendo formada a partir da costela de Adão (Genesis, 2,21). É possível, então, imaginar que um corte foi feito entre o capítulo 1 , versículo 28 , e o capítulo 2 , versículo 21. É possível que isto tenha ocorrido mesmo em uma época muito remota, como no IV século antes de Cristo, quando se supõe que o texto escrito tomou uma forma aproximada da atual (Leach, 1983:77). O próprio teor atual do capítulo 1, versículo 28, sustenta esta hipótese: "E Deus os abençoou, e Deus lhe disse: Frutificai e multiplicai-vos, e enchei a terra..." Como seria possível abençoar a ambos e recomendar a multiplicação se Eva ainda não estava criada?

Sicuteri (1986:27), um dos autores utilizados chama a atenção para um detalhe importante: após a criação de Eva, extraída da costela de Adão, este diz: "Esta é agora osso dos meus ossos, e carne da minha carne, esta será chamada Varôa, porquanto do varão foi tomada." Para Sicuteri, a expressão "esta agora" soa como desta vez numa inequívoca referência à uma mulher anterior.

À sua maneira, Eva repetiria o gesto de rebelião de sua antecessora. Deus tinha permitido ao homem comer todas as frutas do jardim, com apenas uma exceção: “Mas da árvore da ciência do bem 
e do mal, d'ela não comerás; porque no dia que d'ela comeres, certamente morrerás" (Genesis, 2,23). Foi exatamente esta interdição que é rompida por Eva. A versão canônica diz que a mulher assim procedeu tentada pela serpente, sob a alegação de que o consumo da fruta proibida a tornaria tão poderosa como Deus. A punição por este ato de desobediência original foi a perda da imortalidade.

Existem, contudo, outras interpretações. Os teólogos modernos acreditam que a serpente foi a forma tomada pelo demônio para tentar Eva. Uma outra versão é a de que Lilith teria se transformado em serpente para tentar Eva e se vingar de Adão. Uma terceira versão faz parte de uma tradição judaica: "a serpente bíblica era um animal astucioso, que caminhava ereto sobre duas pernas, falava e comia os mesmos alimentos que o homem. Quando viu como os anjos prestigiavam Adão, teve ciúme dele, e a visão do primeiro casal tendo relação sexual despertou na serpente o desejo de Eva. Por inspiração de Satã, a serpente persuadiu Eva a comer o fruto proibido e seduziu-a. Como castigo os seus membros foram cortados e ela teve de arrastar sobre o seu ventre, todos os alimentos que comia sabia a pó, e tornou-se a eterna inimiga dos homens... Quando teve relação sexual com Eva, injetou sua peçonha nela e em todos os seus descendentes. Esta peçonha só foi removida do povo de Israel quando estavam no monte Sinai e receberam o Torá (Unterman, 1992:226).

Expulsos do Éden, Adão e Eva tiveram,segundo a versão canônica, dois filhos: Caim e Abel. As causas do fratricídio cometido por Caim são bem conhecidas, por isso passamos para outra versão; "por um paroxismo de ciúme pela não aceitação de sua oferenda e por uma irmã gêmea que Abel desposara, Caim matou o seu irmão". Chamamos a atenção para um elemento novo que surge: a irmã gêmea que fora casada com Abel. Voltaremos a esse assunto posteriormente.

Continuando com a versão de que Caim não era filho de Adão, mas da serpente que seduziu Eva, chegamos ao momento em que foi banido para o leste do Éden. A sua punição era perambular pela terra, sem descanso, sem que ninguém o pudesse matar. Contudo, foi morto por um seu descendente, Lamech que o confundiu com um animal selvagem.

A versão bíblica atual não faz menção ao "parricídio" de La- 
mech, mas nos dá indício que também neste ponto agiram os editores bíblicos. Vejamos o que diz os versículos 23 e 24 do capítulo 8 do Genesis: "E disse Lamech as suas mulheres Ada e Zilla: ouvi a minha voz: vós, mulheres de Lamech, escutai o meu dito, porque eu matei um varão por minha ferida e um mancebo por minha pisadura". "Porque sete vezes Caim será castigado. mas Lamech setenta vezes sete".

A história continua com o nascimento de Seth, a quem é atribuído a descendência de Adão. Leach, em seu artigo "O Gênesis como um mito" admite que podemos analisar o Velho Testamento como um mito pois uma narrativa somente é considerada um mito quando existe uma comunidade de pessoas que acreditam no texto sagrado e acrescenta "que a não racionalidade do mito é a sua verdadeira essência, pois a religião exige uma demonstração de fé que se faz suspendendo-se a dúvida crítica".

Não existe dúvida que do ponto de vista antropológico, o Genesis é um mito de origem que busca explicar o aparecimento do homem e como tal não difere muito de outros mitos, integrantes das diferentes cosmologias existentes, principalmente em dois pontos fundamentais:

1) $O$ mito não visa a explicação do surgimento de toda a humanidade, mas apenas o surgimento de um povo específico, no caso os hebreus. Tal fato explica-se pelo versículo 16 do capítulo 4: "e saiu Caim de diante da face do Senhor, e habitou na terra de Nod, da banda do oriente do Eden". Ou seja, Caim partiu para o Leste e casou com a filha dos homens. Em outras palavras os mitos origens de são sempre etnocêntricos.

2) O mito narra a história do pecado original. É, portanto semelhante a outras narrativas que mostram que o homem perdeu a imortalidade em função de sua própria culpa. Essa culpa pode ser uma escolha mal feita, um ato de desobediência (como no Genesis) ou uma ofensa a um ser sobrenatural. Os índios Tupi - que estudei - seriam imortais se a primeira mulher não tivesse duvidado dos poderes de Mahira, o herói mítico. O texto bíblico relata a dupla desobediência da mulher: Lilith não atende a determinação do Senhor de voltar para Adão; Eva come do fruto proibido e convence a Adão fazer o mesmo.

$O$ pecado original transformou os seres puros, criados por Deus, em seres impuros. A mulher, a principal responsável pela que- 
da, expressa a sua impureza através da própria biologia. Assim o fluxo menstrual é considerado pelos hebreus como uma forma de poluição que exige rituais de purificação para aqueles que são contaminados. Ao se relacionar sexualmente com a serpente, Eva foi contaminada pela terrível peçonha da mesma. Tal contaminação é transmitida a toda sua descendência, tanto aos filhos de Seth como de Caim. Esta peçonha foi retirada do povo de Israel, no monte Sinai, quando Deus estabeleceu um novo pacto com os Hebreus (Êxodo, 34,10-28), conclamando-o a uma forte endogamia.

Enfim, todos os mitos de origens defrontam-se com a questão do incesto. É comum o caso de um casal de gêmeos que dá início a espécie humana. Nesses casos, o mito estabelece uma relação de inversão com as práticas sociais de seus adeptos. A relação sexual consanguínea é permitida aos ancestrais que vivem naquele tempo, mas torna-se uma prática abominável para os mortais comum. O Genesis não escapa desta característica mítica. Mesmo se desprezarmos a pouco conhecida irmã gêmea de Abel, tão cobiçada por Caim, as práticas incestuosas aparecem no Gênesis: Primeiro, com Adão e Eva, filhos de um mesmo Criador, portanto tecnicamente irmãos, e "carne da mesma carne", como proclamou Adão. Segundo, com Seth que gerou a Enos, provavelmente com a parceria de uma mulher filha de Adão. Em uma sociedade fortemente patriarcal e patrilinear como eram os antigos Hebreus, as mulheres são invisíveis nas suas genealogias.

Finalmente, é interessante registrar que os judeus atuais, descendentes dos antigos hebreus, mudaram a sua regra de descendência. Nas genealogias do Velho Testamento só apareciam os nomes dos genitores masculinos. Hoje para ser considerado realmente um judeu é necessário ter uma mãe judia. Esta transformação radical ocorreu ao longo da grande diáspora.

$2^{\circ}$ texto.

O texto "Cultura e biotecnologia: as interpretações populares” publicado na RevistaUSP, $n^{\circ} 58$, junho/agosto, 2003, surgiu a partir da sugestão de um colega, interessado a saber qual a reação popular as grandes conquistas da biotecnologia e da genética, a par- 
tir do final do século XX. Embora seja a antropologia biológica que tem uma interface mais definida com relação às ciências biológicas, cabe também a antropologia cultural discutir esses avanços científicos. Os antropólogos culturais realmente não estão preparados para discutir com os biólogos os temas acima citados. Mas são perfeitamente aptos para analisar as interpretações populares que surgem em decorrência das noticias sobre os avanços científicos.

Embora a motivação do texto tenha sido levantada por notícias recentes, os homens tiveram, durante muito tempo, buscar explicações para os fatos biológicos sem contar com os recursos instrumentais posteriormente desenvolvidos. Foi necessário, por exemplo, a partir de deduções nem sempre corretas, criar teoria capazes de explicar os fatos relacionados com a reprodução biológica. Fatos esses que somente tornaram-se possíveis de explicação, a partir da existência do microscópio, quando a humanidade tomou conhecimento da existência de óvulos e espermatozoides. De fato, muitos milênios antes dessa descoberta, foram as explicações vernaculares ou êmicas que deram origem às sociedades com regras de descendência patrilinear, matrilinear, etc.

Um outro tipo de interpretações populares são aquelas que atribuem importância valorativa às diferenças decorrentes da cor da pele, do formato dos cabelos, formas cranianas e ao dimorfismo sexual. Essas deduções foram as causas determinantes de preconceitos e de racismos, cujos primeiros exemplos são encontrados em períodos antigos da história. Segundo o antropólogo Juan Comas, a mais antiga referência de preconceito contra o negro foi encontrada em um marco mandado erigir pelo faraó Sesóstris III (1887-1849 AC).

No século XIX, essas interpretações errôneas encontraram abrigos nos escritos de Gobineau e Lombroso que acreditavam que determinados fenótipos eram responsáveis por determinados tipos de comportamentos. Tais crenças persistiram ainda no século XX, como as formuladas pelos idealizadores do nazismo, com trágicas consequências para a humanidade.

Podemos, então, imaginar como o bombardeio de noticias sobre o avanço cientifico pode ser interpretado por grande parte da população, carente de um determinado conhecimento cientifico tanto no Brasil, como no exterior. 
Gostaria de começar com um fato real. No inicio dos anos 80, ouvimos a nossa empregada doméstica convocar as crianças da casa para assistir a noticia do nascimento do "filho do profeta". Imaginamos, então, que a noticia da TV se referia alguma nova seita, dessas que costumam anunciar o fim do mundo a cada final de século. Para a nossa surpresa o que ouvimos foi o anúncio do bebê de proveta. Provavelmente existe um mecanismo linguístico que leve uma pessoa que desconheça o significado de uma palavra recorrer a uma mais parecida. Isto é plausível quando sabemos que as consoantes $\mathrm{fe} v \mathrm{v}$ são próximas.

Quando foram divulgadas as noticias sobre a transmissão genética de características fenotípicas, muitos passaram a acreditar que as aptidões profissionais, os talentos artísticos e até o sucesso empresarial, são frutos da transmissão genética. Desprezavam, assim, os fatores sociais e culturais, como as diferenças de experiência de vida, os diferentes processos de socialização e de transmissão de conhecimento que afetam a vida de cada indivíduo; Se a transmissão genética fosse o fator preponderante existiria o risco da hegemonia das sociedades de castas sobre as de castas, o que não ocorre.

A partir de agora, vamos concentrar a nossa atenção nas interpretações leigas de dois fatos importantes: a inseminação artificial e a clonagem humana.

A inseminação artificial é um exemplo interessante porque interfere de forma radical no processo da reprodução biológica. Permite que casais afetados pela esterilidade de um de seus membros possam reproduzir, gerando uma criança que possua as características biológicas de um deles ou de ambos. Interfere no plano da natureza, pois permite a reprodução independentemente de um ato sexual. E possibilita mesmo, para se referir a uma situação extrema, que uma virgem possa ficar grávida, fato este tão explorado por diversas mitologias ao redor do mundo (cf. Leach, 1966).

Quase três décadas depois das primeiras experiências bem sucedidas, a inseminação ainda provoca polêmicas e até mesmo ações judiciais. Ao lidar com temas tão imbuídos de simbolismos como sexo, reprodução, paternidade, maternidade e filiação, ela extrapola os limites da aplicação de uma técnica biológica para invadir 
o domínio da cultura. Ao abolir a gestação para a mãe biológica - no caso da utilização de uma "mãe de aluguel" - suprime o ato de carregar o filho durante nove meses dentro do próprio corpo. Fica com isso excluída de toda uma rica experiência simbólica desenvolvida de maneiras diferentes por diversas culturas.

Existe, porém, o outro lado da moeda. A supressão das emoções decorrente da gravidez atinge a mãe biológica, mas não atinge a mãe de aluguel, aquela que recebe e desenvolve em seu ventre o embrião com o qual não tem nenhum laço biológico. Mas, apesar disso durante os nove meses que abriga o novo ser ela passa a viver, de fato, uma gravidez. Pois a gravidez não é apenas um processo biológico, é também um processo cultural. A grávida passa a comportar como determinam as normas culturais de sua própria sociedade: sente enjoos e desejos, momentos de medo, decorrentes de tabus secularmente estabelecidos. Pelo contrato estabelecido, ela não deveria ter nenhum sentimento de posse em relação a criança que vai desenvolvendo em seu interior. Mas a cultura é um fator interveniente poderoso. Os padrões de comportamento materno, comumente denominados como instintos, passam a dominar as suas emoções. Aquela criança, que não é o fruto de uma relação usual, vive dentro dela, depende de suas substâncias vitais para a sua sobrevivência e, o pior, tem uma intensa e prazerosa comunicação com ela. Portanto, não são raro os casos em que a mãe recusa entregar aos verdadeiros genitores a criança que dentro dela se desenvolveu dando margem a uma questão judicial.

Mas, mesmo no caso em que a entrega é feita, o contrato é cumprido, existe um trauma decorrente da separação criada artificialmente entre um ato que é ao mesmo tempo da natureza, como da cultura. A ciência moderna, ao criar o novo método, separou fatos que, na cultura ocidental contemporânea, são considerados indissociáveis: a concepção, a gestação e o parto. Mas o problema é que no íntimo das mães, tanto a biológica como a de aluguel, essa separação não existe. Enfim, o que parecia ser apenas a aplicação de uma nova tecnologia pode resultar em um drama para as duas mulheres: ser mãe sem passar pela gravidez e pelo parto; ficar grávida e parir sem ser mãe. É por isso que a literatura e a dramaturgia começam a se 
interessar por essas questões. Note-se que este artigo foi publicado dez anos antes da exibição de "Amor à vida"!

A existência de uma mãe de aluguel é um fato novo do ponto de vista biológico, mas não é um fato novo do ponto de vista cultural. Existem sociedades em que existe a separação apontada acima. São as sociedades fortemente patrilineares, como por exemplo, as sociedades tupis, no Brasil, e os lackers, na Birmânia, hoje denominada Miamar, nas quais a criança pertence exclusivamente a linhagem do pai. A mulher considera isso um fato normal, "sendo elas apenas um saco na qual a criança se desenvolve" para utilizar a citação do Padre José de Anchieta referindo-se aos costumes dos Tupinambá. Ela sabe por antecipação que aquela criança pertence a uma outra família e pode até se tornar um inimigo de sua família, Portanto, a relação que desenvolve com a criança durante a gravidez é diferente. Não é raro que em uma briga com o marido ela provoque o aborto. No contrato social que o matrimônio estabelece coube a ela a ela gestar crianças para outra parentela. A sua afetividade ela transmite para os filhos de seus irmãos, que são os seus verdadeiros parentes.

No final do século XX, a ciência conseguiu um feito notável: o sucesso na clonagem de uma ovelha. Essa experiência foi realizada com outros animais. Após os aplausos pela conquista cientifica, teve inicio uma polêmica decorrente da possibilidade teórica da repetição desse fato tendo como objeto seres humanos. Ao lado das preocupações de ordem ética ou religiosa, surgem interpretações equivocadas, frutos do desenvolvimento cientifico, mas que tem as suas bases em manifestações de mitos populares.

A clonagem humana desperta, entre os leigos, o temor de que um cientista maluco, ou um ditador qualquer, a utilize para formar um exercito de indivíduos orientados para o mal. Esse tema foi brilhantemente tratado por Ira Lewin em seu livro Boys from Brazil, escrito nos anos 70, quando a possibilidade da clonagem humana ainda era um fato bastante remoto. Na trama desenvolvida pelo Autor, o vilão é o médico nazista Mengele, que foi acusado de ter realizado experiências cruéis com os prisioneiros de guerra. Após a guerra, segundo o livro, teria fugido para a América do Sul, trazendo con- 
sigo material genético de Adolfo Hitler. O seu objetivo era criar um novo Adolfo Hitler. Com esse material inseminou artificialmente diversas mulheres indígenas paraguaias. Os bebes eram, em seguida, transportados via VARIG - fato este que determinou o título do livro - para os Estados Unidos para serem criados por famílias de classe média com similaridades com a família de origem de Hitler. Em um dado momento, o pai adotivo era eliminado, para que a criança passasse pelo mesmo trauma de orfandade vivido pelo ditador em sua infância. No final do livro, o Autor mostra que as experiências fracassaram. Nenhum boy do Brasil se transformou em um novo Hitler. Sabiamente, procurou mostrar que do ponto de vista da teoria é possível a repetição biolótica de um individuo através da clonagem, é impossível a repetição cultural e social desse indivíduo. Isso porque o original e o seu clone vão viver em épocas diferentes e experimentar situações existenciais totalmente diferentes. O texto de Ira Lewin é interessante e resultou em um filme com o mesmo título, mas de fato ele fala mais de inseminação artificial do que clonagem.

A impressão que se tem é que, na imaginação popular, os clones são feitos adultos. Esquecem que, em primeira instância, a clonagem é um processo de inseminação artificial que deve resultar na produção de um bebê. Este pode ser biologicamente uma cópia do individuo do qual foi retirado o material genético que lhe deu origem. Será do mesmo sexo, terá o mesmo formato da cabeça, o mesmo tipo de cabelo, a mesma cor dos olhos, etc. As semelhanças, contudo, param aí. Será uma pessoa totalmente diferente do doador do material genético. Em primeiro lugar, ambos passaram por diferentes experiências no âmbito doméstico. A família que é a principal responsável pela reprodução social não é capaz de proporcionar o mesmo tipo de experiência até mesmo para um grupo de irmãos. A explicação mais simples para este fato baseia-se nas mudanças que ocorrem no ciclo de vida do casal de genitores. A imaturidade e falta de experiência que estão presente na época do nascimento dos primeiros filhos, vão sendo substituídas pela maturidade e maior segurança na educação dos filhos menores.

Em segundo lugar, as diferenças entre o doador e a sua cópia decor- 
rem das mudanças culturais da própria sociedade, além da maneira como cada indivíduo consegue se relacionar com o ambiente extrafamiliar.

Independentemente da clonagem, um individuo pode ser fisicamente muito semelhante ao seu avô, mas agem diferentemente porque viveram em épocas diferentes.

Portanto, os temores relativos a clonagem não tem um fundamento sólido. A ciência pode ter o poder para reproduzir o individuo biológico, mas a pessoa é um resultado de processos sociais e culturais.

Podemos ainda imaginar uma situação extrema que com certeza iria de encontro, de uma forma mais radical, aos anseios das adeptas do que, a partir do final do século XX, passou a ser chamado de "produção independente". Seria esta a possibilidade da mulher ter um filho independentemente de qualquer tipo de material genético masculino. Brincando nos limites do absurdo (?), esta seria uma situação que iria além dos anseios contidos no mito das Amazonas.

Finalmente, gostaria de salientar um outro aspecto relacionado com a possibilidade da clonagem: o anseio humano da reconquista da imortalidade. Com efeito, na maioria dos mitos cosmológicos, o homem foi criado imortal, mas perdeu essa característica em função de um erro seu (Remeto ao teor do primeiro texto apresentado). A impossibilidade de conquistar novamente a imortalidade criou diversos artifícios compensatórios. Um deles foi imaginar ou acreditar que uma pessoa possa viver em diferentes gerações. Existem sociedades que uma criança não apenas recebe o nome de seu falecido avô, mas é considerado como a própria reencarnação de seu antepassado. Tal fato pode explicar as sociedades antigas que falam da existência de pessoas que teriam vivido 800 ou 900 anos. Ou seja, vários indivíduos que viveram a vida de uma mesma pessoa.

Mas, o mecanismo compensatório mais comum - à perda da imortalidade - é a admissão que um homem continua vivo na lembrança de seus descendentes. E nesse caso a clonagem poderia ser a forma mais acurada de perpetuação. Assim podemos imaginar que no futuro, algumas pessoas desejem obter algum tipo de "imortalidade" através de descendentes que, pelo menos do ponto de vista biológicos, sejam as suas "cópias" perfeitas. 
Concluindo, esclarecemos que não foi a nossa intenção discutir questões éticas e mesmo as consequências biológicas das novas biotecnologias. Essas discussões já existem e têm contribuído para que as legislações de vários países proíbam ou controlem as experiências com a clonagem humana. Mas até quando será possível coibir essas experiências? O geneticista brasileiro Clodovaldo Pavan (1919-2009) - que foi Presidente da Sociedade Brasileira de Progresso para a Ciência e Presidente do Conselho Nacional de Desenvolvimento Cientifico - acreditava que logo surgiriam os "paraísos clonais" onde essas experiências seriam feitas. Enfim, é muito difícil conter a curiosidade humana.

\section{$3^{\circ}$ Texto.}

Em 1996, publiquei um texto denominado "Um Exercício de Álgebra de Parentesco”, na Série Antropologia, n² 204, da Fundação Universidade de Brasília. Carl Sagan, astrônomo americano, morreu em junho de 1996, deixando prontos os originais do livro Bilhóes e bilhões, publicado em 1997, nos Estados Unidos. Em 1999, ao ler a versão brasileira, publicada em 1998, chamou a minha atenção o capítulo "O tabuleiro de xadrês persa”, em que Sagan trata de números exponenciais.

$O$ trecho é o seguinte: "Todo mundo tem dois pais, quatro avós, oito bisavós, dezesseis trisavós, etc. A geração que retrocedemos, temos duas vezes mais antepassados em linha direta. Pode-se ver que é um problema muito semelhante de xadrez persa. Se cada geração trem, vamos dizer, 25 anos, 64 gerações atrás equivalem a $64 \times 25=1600$ anos, isto é pouco antes da queda do Império romano. Assim, cada um de nós que está vivo hoje tinha, no ano 400, uns 18,5 quintilhão de ancestrais - ou é o que parece. E isso sem falar nos parentes colaterais. Mas isso é muito mais do que a população da Terra então, ou agora; é muito mais do que o número total de seres humanos que já viveram. Alguma coisa está errada com o nosso cálculo. O que? Bem, supusemos que todos esse ancestrais em linha direta fossem pessoas diferentes. Somos repetida e multiplamente ligados a cada um de nosso parentes - um imenso número de vezes, 
no caso dos parentes mais distantes".

Por coincidência, esse havia sido o assunto do meu texto acima referido. A comparação com o de Sagan mostra que o astrônomo e o antropólogo tiveram o mesmo espanto e chegaram a mesma conclusão, mas o tratamento antropológica dado a questão fez a diferença.

Tudo começou quando, em férias no litoral fluminense no início da década de 90, folheei um almanaque gratuito, distribuído por um laboratório farmacêutico. No mesmo, encontrei a seguinte questão: "Você sabe qual o número de seus antepassados até a época que Jesus Cristo viveu?". Na linha seguinte vinha a fabulosa resposta: 1.127.313.685.386,496, número que pode ser lido como um quintilhões, 127 quatrilhões, 313 trilhões, 311 bilhões e os quebrados restantes!

A lógica que levou a esse número prodigioso baseia-se, segundo o próprio almanaque, no tempo decorrido desde a época em que Cristo teria vivido (arredondado para 20 séculos ou dois mil anos) e na possibilidade da existência de três gerações por século, o que totaliza 60 gerações (Sagan considerou quatro gerações por século). O cálculo do almanaque nada mais é que uma progressão geométrica, que toma por base as duas pessoas (pai e mãe) da primeira geração ascendente chegando ao referido número na sexagésima.

A primeira ideia que me veio a cabeça foi a fábula persa do tabuleiro de xadrez. Segundo essa fábula um rei resolveu premiar um súdito, que teria salvo a princesa. Esse lhe pediu uma coisa muito simples aparentemente: que o rei lhe desse um grão de trigo para o primeiro quadrado do tabuleiro, dois para o segundo e assim por diante, de forma que cada quadrado sempre tivesse o dobro de grãos do quadrado anterior. Como o tabuleiro de xadrez tem 64 quadrados, entende-se porque o rei não foi capaz de atender ao pedido. O economista e demógrafo inglês Thomas Maltus (1766-1834) também ficou surpreso ao perceber que 32 duplicações de uma casa atingia um número fabuloso.

Perplexo pela grandeza do número apresentado, concordei de inicio com o cálculo realizado. Tempos depois constatei que existiam três erros cometidos pelo autor do almanaque. Primeiro, o número colocado como resultado final estava errado: referia-se apenas ao número de antepassados existentes na $60^{\mathrm{a}}$ geração ascendente. Segundo, o 
calculista deveria somar a esse número o total dos antepassados nas 59 gerações anteriores, $\mathrm{O}$ resultado, então, seria um número muito maior. Terceiro, o Autor da questão ignorou o fato de que naquela época a população da Terra era muito menor do que a atual.

Assim, uma despreocupada leitura de férias tornou-se um intrigante quebra-cabeça. Os dados apresentados eram inquestionáveis. Por outro lado, a soma de todos os seres humanos que viveram e dos que ainda vivem é um número muito menor. Apontar os erros foi fácil, o difícil foi encontrar a solução.

Como antropólogo que estudou alguns grupos da floresta tropical que se caracterizam por ter populações reduzidas, resolvi fazer um exercício. Escolhi um informante Surui, grupo do sudeste do Pará, constante de genealogias que coletei entre eles, e formulei a seguinte questão: qual seria o número de seus antepassados, no momento em que Pedro Alvares Cabral chegou ao Brasil?

Considerei três gerações por século e limitando o número de anos a 500, obtive como resposta 32.766 antepassados. Esse número é muito maior do que um grupo da floresta tropical, mesmo antes da chegada dos portugueses. A questão parecia continuar insolúvel, mas a natureza do parentesco Suruí, semelhante a de outros grupos da floresta, é muito diferente da dos brasileiros não indígenas.

Em um sistema matrimonial que privilegia o casamento entre primos cruzados (filhos do irmão da mãe e da irmã do pai), muitos antepassados são compartilhados pelos cônjuges. Nesse sistema, os cônjuges têm os mesmos avôs e as mesmas avós. Tal sistema estabiliza o número de ancestrais por geração, a partir da segunda geração ascendente (desde que todos ancestrais tenham seguido a regra de casamento com a prima cruzada).

Em outras palavras, nosso individuo teria dois antepassados na primeira geração ascendente (pai e mãe); quatro na segunda geração ascendente (avô e avó paternos e avô e avó materna) e a partir daí, sempre quatro antepassados. Assim, em 20 séculos, teria apenas 238 pessoas como antepassados diretos. Em outras palavras, o número de ascendentes na sexagésima geração seria igual ao da segunda geração.

É evidente que esse modelo só é válido com a prevalência das 
regras matrimoniais durante todo o período (sem qualquer variação) e se tomarmos como antepassados apenas os ascendentes diretos. Além disso, o número de antepassados pode variar para mais dependendo da existência de poliandria (em que a mulher casa com mais de um homem) ou poliginia (em que um homem casa com mais de uma mulher) e outras relações de parentesco nos casamentos. Outros fatores também podem alterar esses números: uma pessoa pode chamar de avô todos os irmãos do avô e de avó todas as irmãs das avós. Mas quaisquer que sejam as variações o resultado seria insignificante se comparado com os números apresentados no almanaque.

Nesse ponto podemos imaginar dois modelos: o do almanaque (matrimônios entre pessoas sem qualquer parentesco) e o proposto logo acima. É possível representar esses dois modelos por pirâmides demográficas. A primeira seria uma pirâmide invertida, cuja extremidade inferior é igual a 2 e uma extensa base superior igual a um número astronômico. A segunda figura é até difícil de ser chamada de pirâmide, pois parece muito mais um longo retângulo tendo apontada a base inferior.

É esse segundo modelo que torna possível a admissão de um número viável de antepassados em um mundo, então, escassamente povoado, para os seus descendentes que vivem em um mundo extremamente povoado. A combinação da questão com a observação das pequenas sociedades indígenas permite supor que na maior parte da história da humanidade prevaleceu o sistema matrimonial de preferência pelos primos cruzados. Todos sabemos que esse sistema tem a propriedade de transformar parentes que são consanguíneos em uma geração em parentes afim na outra geração, utilizando-se de um universo demográfico extremamente reduzido.

Alem do casamento com primos, os compartilhamentos de ancestrais ocorrem em sociedades que privilegiam outras formas de matrimônios entre parentes próximos. A poligamia é uma dessas outras formas. Façamos um exercício tomando como referência quatro mulheres. Em uma sociedade monogâmica, elas casariam cada uma com um homem, resultando em quatro casais. Quatro casais resultam em 16 pessoas na primeira geração ascendente. Imaginamos agora que essas quatro mulheres pertençam a uma sociedade que admite a po- 
liginia e que todas elas sejam esposas de um mesmo homem - nesse caso o total de ancestrais na primeira geração anterior fica reduzido a dez. Pode ocorrer, ainda, um maior compartilhamento de ancestrais se essa sociedade além de poligênica, adotar a regra da poliginia sororal. Nesse caso, as quatro mulheres seriam irmãs e a primeira geração ascendente ficaria reduzida a apenas quatro ancestrais.

Continuando a nossa busca por regras redutoras de antepassados encontramos a denominada sororato: a primeira esposa morre e o viúvo contrai matrimônio com uma irmã da mesma, mantendo inalterada a primeira geração ascendente. A contrapartida do sororato é o levirato, ou seja, o casamento da viúva com o irmão do falecido.

Existem fortes evidências empíricas que essas regras matrimoniais não estão restritas apenas as chamadas sociedades do tipo tribal. $\mathrm{Na}$ sociedade tradicional brasileira, por exemplo, era fortemente estimulado o casamento com a prima. "A prima é a primeira namorada" diz um ditado popular. Esse estímulo está registrado no poema "Romance de primos e primas", de Carlos Drumond de Andrade: "A prima nasce para o primo. O casamento foi marcado no ato mesmo da concepção..." (Boitempo). Além disso, não eram raros os casamentos com a filha da irmã. Como exemplos, podemos citar Duque de Caxias e Visconde de Mauá. Ambos eram casados com sobrinhas.

$\mathrm{Na}$ Europa era comum o casamento entre primos. Emma, a esposa de Charles Darwin era sua prima de primeiro grau e o irmão dela era casado com a irmã de Darwin. Aliás, a frequência desse tipo de casamento, e suas possíveis consequências, sempre preocuparam Darwin. Seu filho George fez uma análise estatística dos casamentos entre primos e descobriu que eram três vezes mais frequentes nas camadas superiores da Inglaterra.

Tudo indica que as formas matrimoniais que privilegiavam um compartimento maior de ancestrais começaram a desmoronar, no mundo ocidental, a partir do século 18 e 19 quando houve um súbito aumento da população mundial, após centenas de anos de crescimento mínimo. Começou, então, a grande transição descrita pelo sociólogo e demógrafo americano Kinsgley Davis (1908-1997), da passagem das sociedades familiais para as individualistas. Uma das 
fortes características das sociedades individualistas é a predominância dos casamentos determinados pelo "amor românico", que leva os jovens a buscar cônjuges fora de suas parentelas, o que aumenta o número de ancestrais de seus filhos.

Concluindo, a resposta que buscávamos para resolver a questão que nos preocupou, a partir da leitura do inocente almanaque, é o compartilhamento de ancestrais, alem de um complexo entrecruzamento das árvores genealógicas. De qualquer forma, por maior que seja a base da pirâmide etária (somos agora mais de seis bilhões), a humanidade não deixará de compartilhar os seus ancestrais mais longínquos, como aqueles que acenderam, pela primeira vez, uma fogueira na solidão da imensa savana africana.

\section{REFERÊNCIAS:}

CAMPBELL Jr., J.; FREEDMAN, D. N.; MALKOWKI, E. The Biblical archaeologist. New York: A Doubleday Anchor Original, 1970.

CLASTRES, P. A Sociedade contra o Estado. Rio de Janeiro: Francisco Alves, 1978.

COMAS, J. Manual de Antropologia Física. México: Fundo de Cultura Económica, 1953.

DAMATTA, R. Edmund Leach. São Paulo: Ática, 1983.

FOX, R. L. Bíblia, Verdade e Fiç̧ão. São Paulo: Companhia das Letras, 1993.

GRAVES, R., \& PATAI, R. Hebrew Myths. The book of Genesis. New York: Greenwich House, 1983.

LARAIA, R. de B. Tupi, Índios do Brasil Atual. São Paulo: FFLCH/USP, 1983.

LEACH, E. Levi Strauss in the Garden of Eden. In: HAYES, E. N \& HAYES, T. Claude Levi-Strauss: a anthropologist as hero. Cambridge, MA: The M.I.T. Press, 1970.

. A Legitimidade de Salomão, Nascimento Virgem e Genesis enquanto um mito. In: Da MATTA (Ed.). Edmund Leach. São Paulo: Ática, 1983. 
MACFARLANE, A. A História do Casamento e do Amor. São Paulo: Copanhia das Letras, 1990.

MELATTI, J. C. Nominadores e Genitores: um aspecto do dualismo Kraho. Verhandlugen dês XXXVIII Internationalen Americanistenkongresses Stutgasrt-München 12.bis 18. August,1968.

MURDOCK, G. Social Structure. NewYork: MacMillan, 1960.

MUSAPH-ANDRIESSE, R. From Torah to Kabbalah. A Basic Introduction to the writing of Judaism. New York: Oxford University Press, 1981.

SANGAN, C. Bilhões e bilhões. Reflexões sobre a vida e a morte na virada do Século. São Paulo: Companhia das Letras, 1998.

SICUTERI, R. Lilith. A Lua Negra. São Paulo: Paz e Terra, 1986.

PAULY, J. (Org.). Il libro dello Zohar. Roma: Atanor, 1978.

UNTERMAN, A. Discionário Judáico de Lendas e Tradições. Rio de Janeiro: Jorge Zahar Editor, 1992.

Recebido: 26/03/2014.

Aprovado: 30/04/2014. 